\title{
VARIATIONS OF RENAL ARTERY IN CADAVERS
}

\author{
Lama CP, Pradhan A
}

Department of Human Anatomy, Nepal Medical College Teaching Hospital, Attarkhel, Gokarneshwor-8, Kathmandu, Nepal.

\begin{abstract}
Each kidney is usually supplied by a single renal artery which is a lateral branch of abdominal aorta at the level of L1.The arteries supplying the kidneys show variation in the number, source and branching pattern which also include the presence of an accessory or additional and aberrant renal arteries. The additional renal artery towards the lower pole will cross the corresponding ureter and even cause ureteric obstruction. The segmental branches of renal and additional renal arteries are end arteries thus the accidental damage to these arteries can cause ischaemia or necrosis and other pathological conditions. The main objective of this study was to note the variations of the arteries supplying the kidneys. An observational study was conducted on thirty kidneys of fifteen cadavers which included the kidneys of both sides. The study was conducted in Department of Anatomy of Nepal Medical College Teaching Hospital during the period between July 2018 to June 2019 and the variations were recorded as (a) single main renal arteries were found in $80 \%$ specimens on both sides (b) early division of main renal arteries were found in $16.66 \%$ on both sides (c) origin of main renal arteries were at higher level on left side in $16.66 \%$ (d) presence of additional renal arteries were found in $20 \%$ on both sides. This study will be helpful to urosurgeons and also to radiologists performing various interventional radiological procedures.
\end{abstract}

\section{KEYWORDS}

Aberrant renal artery, accessory renal artery, additional renal artery, variation

\section{CORRESPONDING AUTHOR}

Dr. Chhiring Palmu Lama,

Department of Anatomy,

Nepal Medical College Teaching Hospital, Attarkhel,

Gokarneshwor-8, Kathmandu, Nepal

Email: drcpalmu@yahoo.com

ORCID ID: 0000-0003-2560-8816 


\section{INTRODUCTION}

The kidneys are a pair of excretory organs which excrete end products of metabolism and excess water. They are situated posteriorly behind the peritoneum on each side of the vertebral column. Each kidney is supplied by a renal artery which is a branch from the lateral side of abdominal aorta usually at the level of L1 vertebra. ${ }^{1}$ These renal arteries show variation in the number, and also in their origin from abdominal aorta. ${ }^{2}$ They consume around $20 \%$ of the total cardiac output. ${ }^{3}$

During embryogenesis, the kidneys ascend from the pelvic region to the lumbar region. During their ascent they are supplied by several segmented arteries extending from internal iliac artery to the dorsal aorta. The lower vessels usually disappear and some may persist. Persistence of those arteries will result in accessory renal arteries which will cross the corresponding ureter and may cause ureteric obstruction. ${ }^{4}$ There are different terminologies related with accessory and aberrant renal arteries. An accessory renal artery is one which is accessory to the main renal artery, usually arising from abdominal aorta and entering the kidney through the hilum however aberrant renal arteries enter the kidney through either pole whether derived from main renal artery, aorta or a branch from abdominal aorta. ${ }^{5}$

The segmented branches of renal arteries and the accessory renal arteries are end arteries. If an accessory artery is damaged or ligated accidentally, the part of the kidney supplied by it will be ischaemic or necrosed. ${ }^{6}$

A kidney transplantation with variation in the renal artery may cause an acute tubular necrosis, rejecting episodes and decrease graft function. ${ }^{7}$ In most of the cases these variations are noted only at the time of interventions. ${ }^{8}$ With the advancement of interventional and therapeutic urological procedures these days awareness in these variations become important for the urosurgeons to minimize the accidental bleeding during surgeries or prevention of rejection and poor graft functions. ${ }^{9}$ There are scanty literatures available about the variations of renal artery amongst Nepalese population. Hence, this study was undertaken which will be helpful to urosurgeons and also to the radiologists performing various endourologic procedures and it can also be used as an important guideline for academic purposes.

\section{MATERIALS AND METHODS}

The study was started after getting the ethical approval from Institutional Review Committee of Nepal Medical College. An observational study was conducted on thirty kidneys of fifteen cadavers in the Department of Anatomy of Nepal Medical College from July 2018 to June 2019. The study was carried out during the routine dissection procedure of medical students. The kidneys of both sides were included and those having damaged renal arteries were excluded from the study. During dissection, the abdominal cavity was opened up, all the visceras were gradually taken out and were preserved in formalin. The posterior abdominal wall was exposed and the dissection was carried out to explore the vascular supply of kidney along the length of the abdominal aorta. ${ }^{16}$ The renal artery and its variations in origin and branching pattern and the presence of accessory renal arteries and their variations were noted and recorded. Photographs were taken. The frequencies of their variations were calculated.

\section{RESULTS}

Thirty cadaveric kidneys with the arteries supplying them were dissected meticulously in situ. The frequencies of variations of main renal arteries were observed on both sides and were tabulated. (a) The main single renal artery arising from abdominal aorta were found in $80 \%$ on both sides (Table 1 and 2) which have also been shown in Fig. 1. (b) early division of the main renal arteries were found in $16.66 \%$ on both sides (Table 1 and 2) and Fig. 2. (c) origin of main renal arteries were found at higher level in $16.66 \%$ on left side (Table 2). and Fig. 3.

Table 1: Frequency distribution of variations of main renal arteries on right side

\begin{tabular}{|c|c|c|c|c|c|}
\hline \multirow[b]{2}{*}{ S.N. } & \multirow[b]{2}{*}{$\begin{array}{l}\text { Total no. of } \\
\text { specimens }\end{array}$} & \multirow{2}{*}{$\begin{array}{l}\text { Total no. of } \\
\text { single main } \\
\text { renal artery }\end{array}$} & \multicolumn{2}{|c|}{ Level of origin } & \multirow{2}{*}{$\begin{array}{c}\text { Early division } \\
\text { (proximal to } \\
\text { hilum) }\end{array}$} \\
\hline & & & $\begin{array}{l}\text { At the level of } \\
12^{\text {th }} \text { thoracic } \\
\text { vertebra }\end{array}$ & $\begin{array}{l}\text { At the level of } \\
\text { intervertebral disc } \\
\text { between } L 1 \text { and } L 2\end{array}$ & \\
\hline 1. & 15 & $12(80 \%)$ & None & $12(100 \%)$ & $2(16.66 \%)$ \\
\hline
\end{tabular}


Table 2: Frequency distribution of variations of main renal arteries on left side

\begin{tabular}{|c|c|c|c|c|c|}
\hline \multirow{2}{*}{ S.N. } & \multirow{2}{*}{$\begin{array}{l}\text { Total no. of } \\
\text { specimens }\end{array}$} & \multirow{2}{*}{$\begin{array}{l}\text { Total no. of } \\
\text { single main } \\
\text { renal artery }\end{array}$} & \multicolumn{2}{|c|}{ Level of origin } & \multirow{2}{*}{$\begin{array}{c}\begin{array}{c}\text { Early division } \\
\text { (proximal to } \\
\text { hilum) }\end{array} \\
2(16.66 \%)\end{array}$} \\
\hline & & & $\begin{array}{l}\text { At the level of } \\
12^{\text {th }} \text { thoracic } \\
\text { vertebra }\end{array}$ & $\begin{array}{c}\text { At the level of } \\
\text { intervertebral disc } \\
\text { between L1/L2 }\end{array}$ & \\
\hline 1. & 15 & $12(80 \%)$ & $2(16.66 \%)$ & $10(83.33 \%)$ & \\
\hline
\end{tabular}

We also recorded the presence of additional renal arteries and aberrant renal arteries on both sides. $20 \%$ additional renal arteries were noted on both sides (Table 3 and 4).The source of origin of additional renal arteries were from main renal artery in $66.66 \%$ on right side which were seen were found on both sides in same cadaver (Fig.2). while on some other cadaver, there was aberrant renal artery arising from main renal artery and accessory renal artery arising from abdominal aorta in same cadaver. (Fig 3).

\section{Table 3: Frequency distribution of variations of additional renal arteries on right side}

\begin{tabular}{|llcccc|} 
S.N. & $\begin{array}{l}\text { No. of additional } \\
\text { renal arteries on } \\
\text { right side }\end{array}$ & $\begin{array}{c}\text { Origin of additional renal } \\
\text { arteries on right side }\end{array}$ & \multicolumn{2}{c|}{ Branching pattern } \\
1. & $\begin{array}{c}\text { From } \\
\text { abdominal } \\
\text { aorta }\end{array}$ & $\begin{array}{c}\text { From main } \\
\text { renal artery }\end{array}$ & $\begin{array}{c}\text { Towards the } \\
\text { upper pole } \\
\text { (aberrant) }\end{array}$ & $\begin{array}{c}\text { Towards the hilum } \\
\text { (accessory) }\end{array}$ \\
\hline
\end{tabular}

Table 4: Frequency distribution of variations of additional renal arteries on left side

\begin{tabular}{|c|c|c|c|c|c|}
\hline S.N. & $\begin{array}{l}\text { No. of additional } \\
\text { renal arteries on } \\
\text { left side }\end{array}$ & \multicolumn{2}{|c|}{$\begin{array}{l}\text { Origin of additional renal } \\
\text { arteries on left side }\end{array}$} & \multicolumn{2}{|c|}{ Branching pattern } \\
\hline \multirow{2}{*}{1.} & $3(20 \%)$ & $\begin{array}{l}\text { From abdominal } \\
\text { aorta }\end{array}$ & $\begin{array}{l}\text { From main } \\
\text { renal artery }\end{array}$ & $\begin{array}{l}\text { Towards the lower } \\
\text { pole (aberrant) }\end{array}$ & $\begin{array}{l}\text { Towards the hilum } \\
\text { (accessory) }\end{array}$ \\
\hline & & $3(100 \%)$ & None & $2(66.66 \%)$ & $1(33.33 \%)$ \\
\hline
\end{tabular}

entering the upper pole of right kidney (Fig.3) and they were aberrant arteries (Table 3). In 33.33\% the source of origin of additional renal artery was from abdominal aorta on right side which was found entering the hilum and it was an accessory artery (Table 3). Similarly on left side, the source of origin of additional renal artery were from abdominal aorta in all the specimens (100\%) among them aberrant renal arteries were found in $66.66 \%$ and accessory were found in $33.33 \%$ (Fig. 3 and 4).

Interestingly in some of the cadavers, the additional renal arteries arising from abdominal aorta and an early division of main renal arteries

\section{DISCUSSION}

\section{Variations in main renal artery}

According to the standard textbook of Anatomy, each kidney is supplied by a single renal artery in $70 \%$ of individuals with the left renal artery slightly higher than the right and the accessory renal arteries are common in $30 \%$ of individuals. ${ }^{1}$ Many studies have been conducted in renal arteries regarding its variations in the number, level of origin and its branching pattern as the knowledge of variations of renal vascular anatomy is important during the exploration and treatment of renal trauma, renal artery stenosis and is also important during the uroradiological 
procedures. The studies have also shown that the transplantation of kidney with the single renal artery is technically easier as compared to the kidney with multiple arteries. ${ }^{15}$ Other than the cadaveric study the various other methods of studies used were renal artery angiogram and multi - detector computed tomographic angiography.

In the present study a single main renal artery was found in $80 \%$ specimens on both sides (Table 1 and 2) which was similar with the

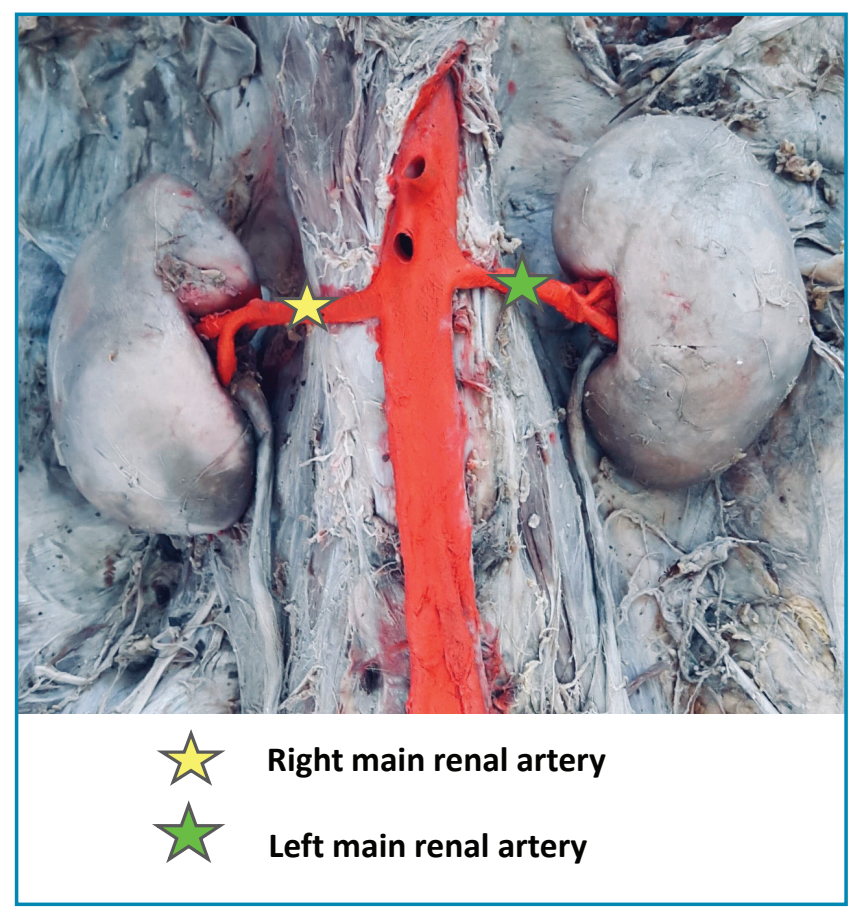

Fig 1: Shows the origin of single main renal artery from abdominal aorta with an early division on both side

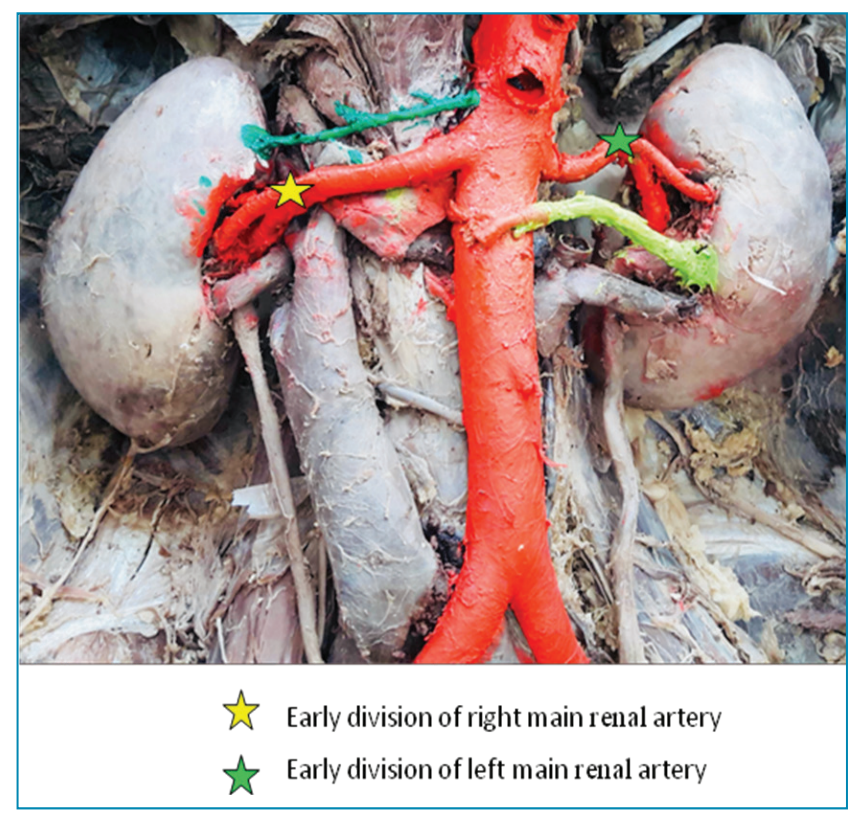

Fig. 2: shows the same level of origin of main renal artery with an early division on both side

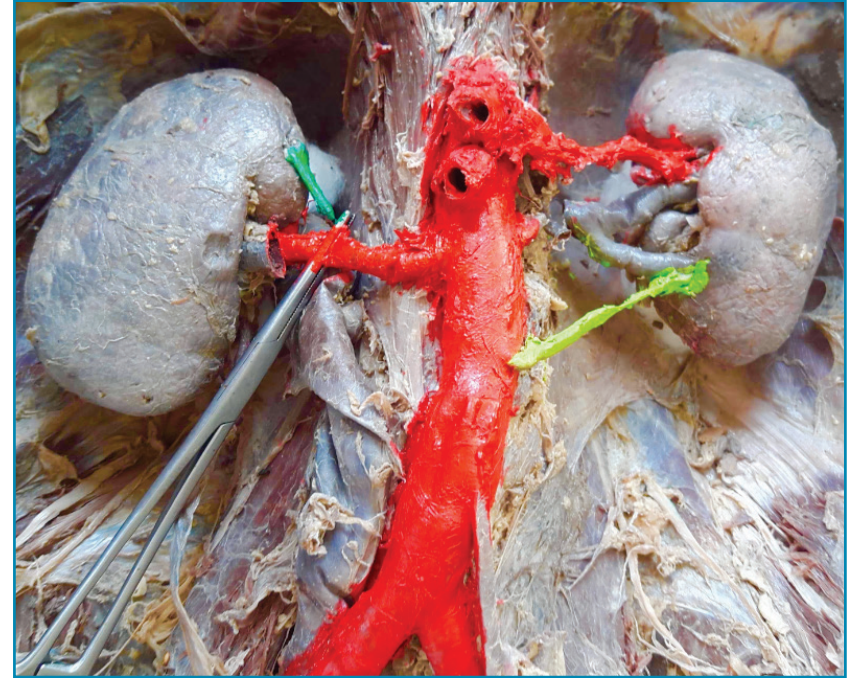

Fig. 3: shows the presence of accessory renal artery on left side arising from abdominal aorta (light green ) and an aberrant renal artery arising from main renal artery on right side (dark green)

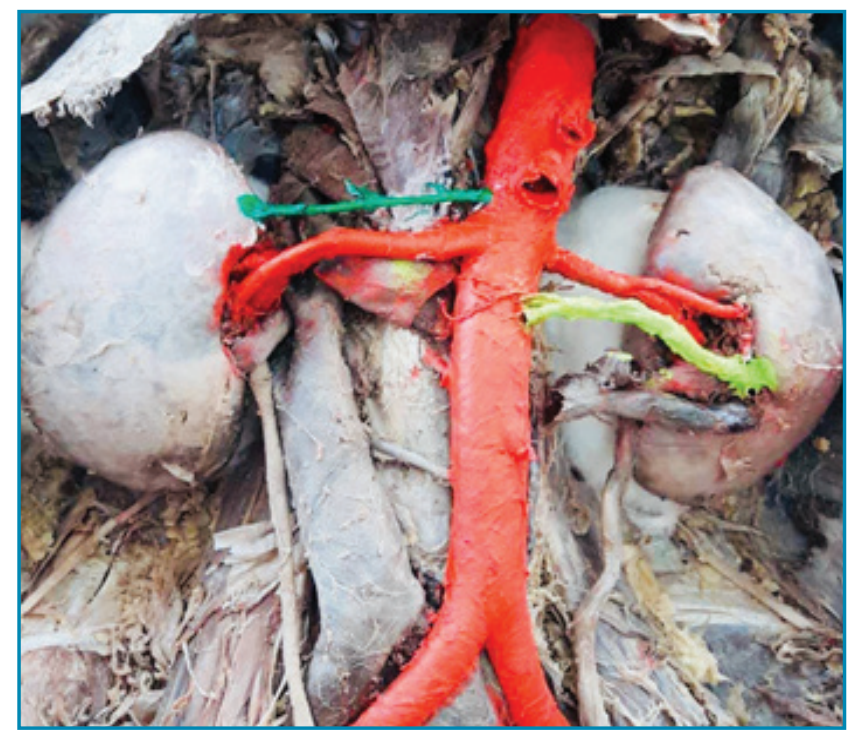

Fig. 4: shows the presence of an accessory renal artery on left side (light green) and an aberrant renal artery arising from abdominal aorta on right side (dark green)

studies by other observers conducted in various countries. ${ }^{10,18,27}$ The origin of left renal arteries were found to be at higher level in $16.66 \%$ (Table 2 ) which was similar with the studies conducted in India by various authors. ${ }^{15,16}$ The higher level of origin on left side has been shown in Fig.3. Branching of main renal arteries into anterior and posterior division proximal to the hilum is called early division. ${ }^{10}$ In the present study, early division was found in $16.66 \%$ on both sides ( Table 1 and 2). Early division of main renal artery has been shown in Fig.2. The divisions were normal in $83.34 \%$ which was very similar with the studies conducted in India and Turkey. ${ }^{10,16}$ 


\section{Variations in additional renal arteries}

The presence of accessory or additional renal arteries are common and are regarded as the persistent embryonic lateral splanchnic arteries. Among them the presence of inferior polar arteries are extremely important as they cross the corresponding ureter and may cause ureteric obstruction. ${ }^{4}$ There are different terminologies related with accessory and aberrant renal arteries. Our findings in the variations of additional renal arteries were found to be similar with the findings of other authors. ${ }^{14,16,20}$ but however they were found to be lower than the studies observed by angiographic method when compared on each side. ${ }^{10}$

In conclusion, the present study showed the wide spectrum of variations in the renal artery and also in the presence of additional renal arteries. The variations were noted at the level of origin and also at their division. The additional or extra renal arteries were equally common on both sides and were found arising either from abdominal aorta or from the main renal arteries. And this variation has also occured simultaneously on both sides in the same cadaver. Frequency of accessory renal arteries are also common on both sides. Furthermore, among the aberrant renal arteries, both superior and inferior polar were equally common on both sides. As the wide variations were observed in the renal arteries this study would be of great help to the transplant surgeons involving in donor nephrectomies, to the radiologists performing various interventional radiological procedures and can also be used as an important tool for academic purposes.

\section{ACKNOWLEDGEMENT}

We would like to express our sincere gratitude to Prof. Dr.S.K.Ghosh, Prof. Dr.Shaligram Dhungel, Department of Anatomy for their guidance and support throughout the study. Our sincere thanks also goes to all the faculty members of Department of Anatomy for their continuous support and

help.

\section{REFERENCES}

1. Standring S. Kidney and ureter. The Anatomical Basis of Clinical Practice (41 ${ }^{\text {st }}$ ed.). London: Elsevier 2016: 1243-5.

2. Dhar P, Lal K. Main and accessory renal arteries: a morphological study. Ital J Anat Embryol 2005; 110: 101-10.

3. Johnson PB, Cawich SO, Shah SD et al. Accessory renal arteries in a Caribbean population : a computed tomographic study. Springerplus 2013; 2: 443-5.

4. Sadler TW. Urogenital System. Langman's Medical Embryology (11 $11^{\text {th }}$ ed.).USA: Lippincott Williams and Wilkins 2010: 241-2.

5. Rao TR, Rachana. Aberrant renal arteries and its clinical significance. Int'l J Anat Var 2011; 4:37-9.

6. Moore KL, Persaud TVN, Torchia MG. Urogenital system. Clinically Oriented Embryology (9 $9^{\text {th }}$ ed.). London: Elsevier 2013: 252-3.

7. Sampaio FJ, Passos MA. Renal arteries: anatomic study for surgical and radiological practice. Surg Radiol Anat 1992; 14: 113-7.

8. Krishnaswamy N, Rao M, Somayaji SN, Koshy $\mathrm{N}$, Rodrigues V. An unusual case of unilateral additional right renal artery and vein. Int'l J Anat Var 2010; 3: 9 -11.

9. Gupta V, Kotgirwar S, Trivedi S, Deopujari R, Singh V. Bilateral variations in renal vasculature. Int'l $J$ Anat Var 2010; 3: 53-5.

10. Ozkan U, Oguzkurt L, Tercan F, Kizikilic O, Koc Z, Koca N. Renal artery origins and variations:
Angiographic evaluation of 855 consecutive patients. Diagn Interv Radiol 2006; 12: 183-6.

11. Ogeng’o JA, Masaki CO, Sinkeet SR, Muthoka JM, Murunga AK. Variant anatomy of renal arteries in a Kenyan population. Ann Trans 2010; 15: 40-5.

12. Hlaing KPP, Das S, Sulaiman IM. Accessory renal vessels at the upper and lower pole of kidney : a cadaveric study with clinical implications. Brat Med J 2010; 5: 308-10.

13. Kumar MP, Suseelamma D, Saritha S, Lingaswamy V. Multiple renal vascular variations. Open Access Sci Reports 2012; 1: 334-6.

14. Parmar JK, Gujar S, Vikani S et al. A cadaveric study of variations in renal artery. Int'l J Biomed Adv Res 2012; 3: 815-7.

15. Vaghela BP, Parmar AM, Trivedi BD. Study of morphology of renal artery in 50 human cadavers by dissection method in Ahmedabad district. Indian J App Res 2013; 1: 2249-55.

16. Ankolekar V, Sengupta R. Renal artery variations: a cadaveric study with clinical relevance. Int'l J Cur Res Rev 2013; 5: 154-61.

17. Sinha RR, Kumar B, Kumar A et al. Abnormal anatomical position and number of renal artery at the renal hilum. J Indian Acad Fores Med 2015; 37: 187-9.

18. Rao EV, Battula SR. A study of renal artery variations in cadavers. Asian Pac J Health Sci 2015; 2: 55-61.

19. Banoo S, Bhat GM, Itoo MS et al. Accessory renal arteries and associated variations in the arrangement of structures at the hilum of kidney A cadaveric study. Int'l J Curr Res 2016; 8: 25644 - 7 . 
20. R. Chitra. A study of various types of accessory renal arteries. Int'l J Anat Res 2016; 4: 2522-5.

21. Chauhan P, Khima D, Pandya A, Rathod S. A cadaveric study of renal artery variation in Rajkot. J Med Sci Clin Res 2016; 4: 1006 - 69.

22. Cinar C, Turkvatan A. Prevalence of renal vascular variations: Evaluation with MDCT angiography. Diagn Interv Imaging 2016; 97: 891-7.

23. Nasr K, Hurley M, Olivieri MP, Gervasi M. Anatomical variation of renal artery branching in cadavers. Fed Am Soc Exp Biol J 2017; 896-9.

24. Hassan SS, Sharawya EA, Johnson JC, Youakim
MF, Ettarh R. Incidence of variations in human cadaveric renal vessels. Folia Morphol 2017; 76: 394-7.

25. Animaw Z, Worku A, Muche A. Renal artery origins, destinations and variations: Cadaveric study in Ethiopian population. Int'l J Anat Var 2018; 11: 1-3.

26. Arquez HF. Unusual combination of vascular variations in the retroperitoneal region: a morphological study. Int'l Arch Med 2018; 11: 175582.

27. Khamanarong K, Prachaney $\mathrm{P}$, Utararavivhien A, T Tong-Un, Sripayora K. Anatomy of renal arterial supply: Clin Anat 2004; 17: 334-6. 